\title{
МОДЕЛЮВАННЯ АСИМЕТРИЧНИХ ДИНАМІЧНИХ РЕЖИМІВ ТРИФАЗНИХ ТРАНСФОРМАТОРІВ
}

У статті виконано аналіз аспектів необхідності дослідження динамічних режимів трансформаторів, якіє найважливішим елементом електричних мереж. Розглянуті види математичних моделей, які використовуються для дослідження динамічних режимів трансформаторів. Представлені аргументи на користь трьохосьових математичних моделей, які мають більш иирокі можливості моделювання різних режимів роботи. Ціль статті - визначення універсального варіанта математичної моделі, щзо підходить для дослідження асиметричних режимів роботи трансформатора. У статті запропоновано варіант трьохосьової математичної моделі на основі моделі узагальненої електричної машини. Використано модернізований варіант моделі, який враховує втрати потужності $в$ магнітопроводі. Для можливості моделювання за ї̈ допомогою асиметричних режимів було виконано поділ за фазами параметрів і введено відповідні розрахункові коефіиієнти. Рівняння струмів представлені з урахуванням поділу за фазами їх параметрів. Для отриманої моделі розраховані перехідні прочеси для одного симетричного (включення трансформатора на повне навантаження) $i$ двох асиметричних (включення при короткому замиканні в одній фазі й включення при обриві однісї фази) режимів. В якості джерел асиметрії розглядалися аварії у вторинному колі трансформатора. Моделювання виконувалося на змінному струмі. Аналіз отриманих характеристик показав, щзо запропоновані модель $і$ способи ї̈ застосування дозволяють адекватно змоделювати иирокий спектр динамічних режимів трансформатора без необхідності застосування розкладання асиметричних систем величин на набір симетричних складових, що значно спрощує прочес моделювання. Аналіз асиметричних режимів показав, щзо вони характеризуються асиметрією струмів трансформатора по амплітуді й по фазі, а у випадку обриву фази спостерігається суттєва розбіжність картини струмів у первинній і у вторинній обмотках.

Ключові слова: математична модель, трансформатор, перехідний процес, асиметрія, коротке замкнення, обрив фази.

О.Ю. КИМСТАЧ Национальный университет кораблестроения имени адмирала Макарова, г. Николаев ORCID: 0000-0002-1447-8852

А.О. ЖЕЖЕЛО

Национальный университет кораблестроения имени адмирала Макарова, г. Николаев ORCID: 0000-0003-4969-4659

В.Ю. КУЗЕМА

Национальный университет кораблестроения имени адмирала Макарова, г. Николаев ORCID: 0000-0001-7897-3097

\section{МОДЕЛИРОВАНИЕ АСИММЕТРИЧНЫХ ДИНАМИЧЕСКИХ РЕЖИМОВ ТРЕХФАЗНЫХ ТРАНСФОРМАТОРОВ}

В статье выполнен анализ аспектов необходимости исследования динамических режимов трансформаторов, которые являются важнейшим элементом электрических сетей. Рассмотрены виды математических моделей, которые используются для исследования динамических режимов трансформаторов. Представлены аргументы в пользу трехосных математических моделей, которые имеют более широкие возможности моделирования различных режимов работь. Цель статьи определение универсального варианта математической модели, подходящая для исследования асимметричных режимов работы трансформатора. В статье предложен вариант трехосной математической модели на основе модели обобщенной электрической машинь. Использован модернизированный вариант модели, который учитывает потери мощности в магнитопроводе. Для возможности моделирования с ее помощью асимметричных режимов было выполнено пофазное 
разделение параметров и введень соответствующие расчетные коэффициентьл. Уравнения токов представлены с учетом пофазного разделения их параметров. Для полученной модели рассчитаны переходные процессы для одного симметричного (включение трансформатора на полную нагрузку) и двух асимметричных (включение при коротком замыкании в одной фазе и включение при обрыве одной фазы) режима. В качестве источников асимметрии рассматривались аварии во вторичной цепи трансформатора. Моделирование выполнялось на переменном токе. Анализ полученных характеристик показал, что предложенные модель и способы ее применения позволяют адекватно смоделировать широкий спектр динамических режимов трансформатора без необходимости применения разложения асимметричных систем величин на набор симметричных составляющих, что значительно упрощает процесс моделирования. Анализ асимметричных режимов показал, что они характеризуются асимметрией токов трансформатора по амплитуде и по фазе, а в случае обрыва фазы наблюдается существенное расхождение картины токов в первичной и во вторичной обмотках.

Ключевые слова: математическая модель, трансформатор, переходный прочесс, асимметрия, короткое замыкание, обрив фазы.

O.YU. KIMSTACH Admiral Makarov National University of Shipbuilding, Mykolayiv ORCID: 0000-0002-1447-8852

A.O. ZHEZHELO

Admiral Makarov National University of Shipbuilding, Mykolayiv ORCID: 0000-0003-4969-4659

V.YU. KUZOMA

Admiral Makarov National University of Shipbuilding, Mykolayiv ORCID: 0000-0001-7897-3097

\section{MODELLING OF ASYMMETRICAL DYNAMICAL MODES OF THREE-PHASE TRANSFORMER}

The paper analyses the aspects of the need to research the dynamic modes of transformers, which are the most important element of power grids. The types of mathematical models that are used to research the dynamic modes of transformers are considered. Arguments in favour of 3-axial mathematical models are presented, which have wider possibilities for modelling various operating modes. The paper aims to determine a universal variant of a mathematical model suitable for studying asymmetric operating modes of a transformer. The paper proposes a variant of a 3-axial mathematical model based on a generalized electric machine model. A modernized variant of the model was used, which takes into account the power losses in the magnetic core. To be able to model asymmetric modes with its help, a phase-by-phase separation of parameters was performed and the corresponding calculated coefficients were introduced. The equations of currents are presented taking into account the phaseby-phase separation of their parameters. For the proposed model, transients for one symmetric (switching on the transformer at full load) and two asymmetric (switching on when a short circuit in one phase and switching on when phase failure) modes were calculated. As sources of asymmetry, the accidents in the secondary circuit of the transformer were considered. Modelling was performed on alternating current. The analysis of the obtained curves showed that the proposed model and methods of its application make it possible to adequately model a wide spectrum of dynamic modes of a transformer without the need to use the decomposition of asymmetric systems of quantities into a set of symmetric components, which essentially simplifies the modelling process. The analysis of asymmetric modes showed that they are characterized by an asymmetry of the transformer currents in amplitude and angle, and in the case of a phase failure, a significant difference in the pattern of currents in the primary and secondary windings is observed.

Keywords: mathematical model, transformer, transient process, asymmetry, short-circuit, phase failure.

\section{Постановка проблеми}

Побудова сучасних електричних мереж 3 урахуванням досягнення заданого рівня якості електричної енергії та оптимальних режимів роботи без застосування трансформаторних підстанцій практично неможливо $[1,2]$. Трансформаторна підстанція - основний елемент електричних мереж, котрий забезпечує фільтрацію вищих гармонійних складових та окремих складових асиметричних систем струмів, перетворення напруги та їі систем, електричне розв'язування кіл та ін. При цьому слід враховувати, що трансформатор найбільш коштовний елемент електричних мереж [3], тому його всебічне та досконале дослідження традиційно являє собою актуальне питання.

Трансформатори працюють у статичних та динамічних режимах. Але більш небезпечними являються динамічні режими, котрі можуть супроводжуватися струмами у $10 \ldots 20$ разів більше номінальних значень [4]. Це може викликати коротке замкнення, яке зазвичай складає приблизно $40 \%$ всіх пошкоджень трансформаторів [3], в тому числі до $24 \%$ - руйнування обмоток [5], і, відповідно, порушення нормальних умов роботи електричних мереж. Тому необхідно більш прискіпливо 
досліджувати перехідні процеси, які безпосередньо протікають у трансформаторах. Для цього потрібно отримати та визначити основні умови застосування математичних моделей (ММ) трансформатора, які більш ефективно і максимально універсально забезпечують можливості аналізу довільних типів динамічних режимів трансформаторів, в тому числі асиметричних.

\section{Аналіз останніх досліджень і публікацій}

Питання моделювання різнобічних перехідних процесів в трансформаторах не являється новим, воно досліджувалося довго та з різних боків за допомогою різноманітних ММ. Найбільше поширення отримали двохосьові ММ на базі узагальненої електричної машини [6], які відрізняються найменшою кількістю рівнянь і тому прості у використанні. Але такі ММ придатні лише для наближеного моделювання симетричних перехідних процесів.

Більш широкі можливості мають трьохосьові ММ трансформатора на базі узагальненої електричної машини [6-8], які більш придатні для моделювання силових трифазних трансформаторів, в тому числі асиметричних режимів. Кількість рівнянь в півтори рази більша ніж у двохосьових ММ та більша складність рівнянь робила трьохосьові ММ раніше менш затребуваними, але зростання обчислювальних та програмних можливостей комп'ютерів останнім часом призвело до поширення трьохосьових ММ. Більш того для моделювання трансформаторів та асинхронних машин, ММ котрих споріднена з ММ трансформатора, а в режимі короткого замкнення співпадає, дуже популярним стає застосування прикладного програмного комплексу MATLAB [2, 9-12]. При чому MATLAB використовується як інструмент для вирішення широкого спектру задач, так в роботі [9] розглядається застосування трьохосьової ММ асинхронного двигуна для аналізу неповнофазних режимів роботи, в [10] розглядається трьохосьова ММ асинхронного двигуна для несинусоїдальних струмів, в [2] трансформатор представляється як RLC-елемент електричної мережі, в [11] викладено алгоритм визначення параметрів MM трансформатора за каталожними даними, в [12] наведено приклад аналізу несиметричних навантажень трансформатора. Застосування MATLAB для моделювання надає широкі можливості, але неврахування прийнятих припущень і некоректне використання ММ або чисельних методів, які вбудовані у програмний комплекс, можуть призвести до помилкових результатів, а також обмежують розуміння дослідниками особливостей фізичних процесів окремих нестандартних режимів роботи об'єкту дослідження.

Тому формування ММ трансформаторів для відповідних режимів і їх дослідження за допомогою обчислювальних програмних продуктів, як наприклад MathCad, або засобів програмування надають більш об'єктивний результат.

\section{Формулювання мети дослідження}

Мета роботи - визначення універсального варіанта математичної моделі, який придатний для дослідження асиметричних динамічних режимів трансформатора.

Викладення основного матеріалу досліджень

Для розгляду асиметричних динамічних режимів роботи трифазного трансформатора придатна лише трьохосьова ММ, яка побудована на основі ММ узагальненої електричної машини [6]. Але загальний підхід до моделювання асиметричних режимів може бути побудовано по різному: на основі розкладання асиметричних величин на сукупність симетричних складових (пряму, зворотну та нульову) з послідуючим окремим моделюванням кожної складової [9], використання загальної ММ з урахуванням параметрів, які визначають асиметрію [12]. Іноді при аналізі асиметричної роботи трансформатора виділяється додатково нульова послідовність [13], що надає можливість визначити окремо ії вплив на характеристики та необхідність їі усунення.

В цілому більш універсальним та простим буде застосування загальної ММ з урахуванням факторів асиметрії. Основним джерелом асиметрії роботи трифазного трансформатора являється розбіжність опорів навантажень, особливо це стосується розподільчих підстанцій електричних мереж, які мають багато однофазних споживачів. Відповідно перш за все при побудові ММ трансформатора слід враховувати розбіжність струмів за фазами для первинної та вторинної обмоток.

При побудові ММ трансформатора вважається, що магнітопровід повністю симетричний i магнітні властивості за всіма фазами однакові.

Згідно з [6] побудовано систему рівнянь для потокозчеплень в осях $A B C$

$$
\left\{\begin{array}{l}
\Psi_{1 a}=L_{1 a} i_{1 a}-0.5 M i_{1 b}-0.5 M i_{1 c}+M i_{2 a}-0.5 M i_{2 b}-0.5 M i_{2 c} ; \\
\Psi_{1 b}=L_{1 b} i_{1 b}-0.5 M i_{1 a}-0.5 M i_{1 c}+M i_{2 b}-0.5 M i_{2 a}-0.5 M i_{2 c} \\
\Psi_{1 c}=L_{1 c} i_{1 c}-0.5 M i_{1 b}-0.5 M i_{1 a}+M i_{2 c}-0.5 M i_{2 b}-0.5 M i_{2 a} \\
\Psi_{2 a}=L_{2 a} i_{2 a}-0.5 M i_{2 b}-0.5 M i_{2 c}+M i_{1 a}-0.5 M i_{1 b}-0.5 M i_{1 c} \\
\Psi_{2 b}=L_{2 b} i_{2 b}-0.5 M i_{2 a}-0.5 M i_{2 c}+M i_{1 b}-0.5 M i_{1 a}-0.5 M i_{1 c} \\
\Psi_{2 c}=L_{2 c} i_{2 c}-0.5 M i_{2 b}-0.5 M i_{2 a}+M i_{1 c}-0.5 M i_{1 b}-0.5 M i_{1 a}
\end{array},\right.
$$


де $M$ - взаємна індуктивність; $i_{1 a}, i_{1 b}, i_{1 c}, i_{2 a}, i_{2 b}$ і $i_{2 c}$ - первинні та вторинні струми за осями $A, B$ і $C$ відповідно, повні індуктивності для обмоток обчислюються за формулами [6]:

$$
\begin{aligned}
& L_{1 a}=L_{1 b}=L_{1 c}=L_{1 \sigma}+M ; \\
& L_{2 a}=L_{2 \mathrm{H} a}+M=L_{\mathrm{H} . a}+L_{2 \sigma}+M ; \\
& L_{2 b}=L_{2 \mathrm{H} b}+M=L_{\mathrm{H} . b}+L_{2 \sigma}+M ; \\
& L_{2 c}=L_{2 \mathrm{Hc}}+M=L_{\mathrm{H} . c}+L_{2 \sigma}+M,
\end{aligned}
$$

де $L_{1 \sigma}$ та $L_{2 \sigma}$-індуктивності розсіювання первинної та вторинної обмоток трансформатора; $L_{\mathrm{H} . a}, L_{\mathrm{H} . b} \mathrm{i}$ $L_{\text {н. } c}-$ індуктивності навантажень за осями $A, B$ і $C$.

В даному випадку збіжність кількостей фаз та осей ММ дозволяє вважати відповідно параметри однаковими з урахуванням перерахунку за базовими величинами.

Система (1) розв'язується відносно струмів з урахуванням (2):

$$
\begin{aligned}
& \int i_{1 a}=\frac{3 M L_{2 \mathrm{H} a}}{\sqrt{2} k_{x} L_{1 \sigma}}\left[\frac{1}{L_{1 \sigma}}\left(\Psi_{1 a} a_{1}+\Psi_{1 b} k_{2 c} L_{2 \mathrm{H} b}+\Psi_{1 c} k_{2 b} L_{2 \mathrm{Hc}}\right)+\Psi_{2 a} a_{2}+\Psi_{2 b} k_{2 c}+\Psi_{2 c} k_{2 b}\right] ; \\
& i_{1 b}=\frac{3 M L_{2 \mathrm{H} b}}{\sqrt{2} k_{x} L_{1 \sigma}}\left[\frac{1}{L_{1 \sigma}}\left(\Psi_{1 a} k_{2 c} L_{2 \mathrm{H} a}+\Psi_{1 b} b_{1}+\Psi_{1 c} k_{2 a} L_{2 \mathrm{Hc}}\right)+\Psi_{2 a} k_{2 c}+\Psi_{2 b} b_{2}+\Psi_{2 c} k_{2 a}\right] \text {; } \\
& i_{1 c}=\frac{3 M L_{2 \mathrm{\mu} c}}{\sqrt{2} k_{x} L_{1 \sigma}}\left[\frac{1}{L_{1 \sigma}}\left(\Psi_{1 a} k_{2 b} L_{2 \mathrm{H} a}+\Psi_{1 b} k_{2 a} L_{2 \mathrm{H} b}+\Psi_{1 c} c_{1}\right)+\Psi_{2 a} k_{2 b}+\Psi_{2 b} k_{2 a}+\Psi_{2 c} c_{2}\right] \text {; } \\
& \left\{i_{2 a}=\frac{3 M}{\sqrt{2} k_{x}}\left[\frac{1}{L_{1 \sigma}}\left(\Psi_{1 a}\left(a_{1}-\frac{k_{x} L_{1 \sigma}}{M L_{2 \mathrm{H} a}}\right)+\Psi_{1 b} k_{2 c} L_{2 \mathrm{H} b}+\Psi_{1 c} k_{2 b} L_{2 \mathrm{H} c}\right)+\Psi_{2 a}\left(a_{2}+\frac{k_{x}}{M L_{2 \mathrm{H} a}}\right)+\Psi_{2 b} k_{2 c}+\Psi_{2 c} k_{2 b}\right]\right. \text {; } \\
& i_{2 b}=\frac{3 M}{\sqrt{2} k_{x}}\left[\frac{1}{L_{1 \sigma}}\left(\Psi_{1 a} k_{2 c} L_{2 \mathrm{H} a}+\Psi_{1 b}\left(b_{1}-\frac{k_{x} L_{1 \sigma}}{M L_{2 \mathrm{H} b}}\right)+\Psi_{1 c} k_{2 a} L_{2 \mathrm{H} c}\right)+\Psi_{2 a} k_{2 c}+\Psi_{2 b}\left(b_{2}+\frac{k_{x}}{M L_{2 \mathrm{H} b}}\right)+\Psi_{2 c} k_{2 a}\right] \text {; } \\
& i_{2 c}=\frac{3 M}{\sqrt{2} k_{x}}\left[\frac{1}{L_{1 \sigma}}\left(\Psi_{1 a} k_{2 b} L_{2 \mathrm{H} a}+\Psi_{1 b} k_{2 a} L_{2 \mathrm{H} b}+\Psi_{1 c}\left(c_{1}-\frac{k_{x} L_{1 \sigma}}{M L_{2 \mathrm{H} c}}\right)\right)+\Psi_{2 a} k_{2 b}+\Psi_{2 b} k_{2 a}+\Psi_{2 c}\left(c_{2}+\frac{k_{x}}{M L_{2 \mathrm{Hc}}}\right)\right],
\end{aligned}
$$

де для спрощення вигляду системи струмів використані наступні коефіцієнти:

$$
\begin{aligned}
& a_{1}=\frac{k_{x} L_{1 \sigma}}{M L_{2 \mathrm{H} a}}-k_{2 b} L_{2 \mathrm{H} c}-k_{2 c} L_{2 \mathrm{H} b} ; \\
& a_{2}=\frac{k_{2 b} k_{2 c}}{M}-k_{2 b}-k_{2 c}-\frac{k_{x}}{M L_{2 \mathrm{H} a}} ; \\
& b_{1}=\frac{k_{x} L_{1 \sigma}}{M L_{2 \mathrm{H} b}}-k_{2 a} L_{2 \mathrm{H} c}-k_{2 c} L_{2 \mathrm{H} a} ; \\
& b_{2}=\frac{k_{2 a} k_{2 c}}{M}-k_{2 a}-k_{2 c}-\frac{k_{x}}{M L_{2 \mathrm{H} b}} ; \\
& c_{1}=\frac{k_{x} L_{1 \sigma}}{M L_{2 \mathrm{H} c}}-k_{2 a} L_{2 \mathrm{H} b}-k_{2 b} L_{2 \mathrm{H} a} ; \\
& c_{2}=\frac{k_{2 a} k_{2 b}}{M}-k_{2 a}-k_{2 b}-\frac{k_{x}}{M L_{2 \mathrm{H} c}},
\end{aligned}
$$

де також використані коефіцієнти спрощення:

$$
\begin{aligned}
& k_{2 a}=2 L_{2 \mathrm{H} a}+3 M\left(1+\frac{L_{2 \mathrm{H} a}}{L_{1 \sigma}}\right) ; \\
& k_{2 b}=2 L_{2 \mathrm{H} b}+3 M\left(1+\frac{L_{2 \mathrm{H} b}}{L_{1 \sigma}}\right) ; \\
& k_{2 c}=2 L_{2 \mathrm{Hc}}+3 M\left(1+\frac{L_{2 \mathrm{H} c}}{L_{1 \sigma}}\right) ;
\end{aligned}
$$




$$
\begin{gathered}
k=2 M\left[L_{2 \mathrm{H} a} L_{2 \mathrm{H} b}\left(1+\frac{L_{2 \mathrm{H} c}}{L_{1 \sigma}}\right)+L_{2 \mathrm{H} a} L_{2 \mathrm{Hc}}\left(1+\frac{L_{2 \mathrm{H} b}}{L_{1 \sigma}}\right)+L_{2 \mathrm{Hc}} L_{2 \mathrm{H} b}\left(1+\frac{L_{2 \mathrm{H} a}}{L_{1 \sigma}}\right)\right]+4 L_{2 \mathrm{H} a} L_{2 \mathrm{H} b} L_{2 \mathrm{H} c} ; \\
k_{x}=k+M\left[L_{2 \mathrm{H} a} k_{2 b}\left(1+\frac{L_{2 \mathrm{H} c}}{L_{1 \sigma}}\right)+k_{2 a} L_{2 \mathrm{H} c}\left(1+\frac{L_{2 \mathrm{H} b}}{L_{1 \sigma}}\right)+k_{2 c} L_{2 \mathrm{H} b}\left(1+\frac{L_{2 \mathrm{H} a}}{L_{1 \sigma}}\right)\right] .
\end{gathered}
$$

Для повного формування ММ трансформатора необхідно ще додати вирази похідних потокозчеплень, які отримуються з рівнянь кіл первинної та вторинної обмоток [6],

$$
\left\{\begin{array}{l}
\frac{d \Psi_{1 a}}{d t}=U_{1 a}-r_{1} \cdot i_{1 a}+\frac{\left(\Psi_{1 b}-\Psi_{1 c}\right) \sqrt{3}}{2}-r_{m}\left[i_{1 a}+i_{2 a}-0,5 \cdot\left(i_{1 b}+i_{2 b}+i_{1 c}+i_{2 c}\right)\right] \\
\frac{d \Psi_{1 b}}{d t}=U_{1 b}-r_{1} \cdot i_{1 b}+\frac{\left(\Psi_{1 c}-\Psi_{1 a}\right) \sqrt{3}}{2}-r_{m}\left[i_{1 b}+i_{2 b}-0,5 \cdot\left(i_{1 a}+i_{2 a}+i_{1 c}+i_{2 c}\right)\right] ; \\
\frac{d \Psi_{1 c}}{d t}=U_{1 a}-r_{1} \cdot i_{1 a}+\frac{\left(\Psi_{1 a}-\Psi_{1 b}\right) \sqrt{3}}{2}-r_{m}\left[i_{1 c}+i_{2 c}-0,5 \cdot\left(i_{1 b}+i_{2 b}+i_{1 a}+i_{2 a}\right)\right] ; \\
\frac{d \Psi_{2 a}}{d t}=-r_{2 \mathrm{H} a} \cdot i_{2 a}+\frac{\left(\Psi_{2 b}-\Psi_{2 c}\right) \sqrt{3}}{2}-r_{m}\left[i_{1 a}+i_{2 a}-0,5 \cdot\left(i_{1 b}+i_{2 b}+i_{1 c}+i_{2 c}\right)\right] ; \\
\frac{d \Psi_{2 b}}{d t}=-r_{2 \mathrm{Hb}} \cdot i_{2 b}+\frac{\left(\Psi_{2 c}-\Psi_{2 a}\right) \sqrt{3}}{2}-r_{m}\left[i_{1 b}+i_{2 b}-0,5 \cdot\left(i_{1 a}+i_{2 a}+i_{1 c}+i_{2 c}\right)\right] ; \\
\frac{d \Psi_{2 c}}{d t}=-r_{2 \mathrm{Hc}} \cdot i_{2 a}+\frac{\left(\Psi_{2 a}-\Psi_{2 b}\right) \sqrt{3}}{2}-r_{m}\left[i_{1 c}+i_{2 c}-0,5 \cdot\left(i_{1 b}+i_{2 b}+i_{1 a}+i_{2 a}\right)\right] ;
\end{array}\right.
$$

де $r_{1}$ - активний опір первинної обмотки; $r_{2 \text { на }}, r_{2 н b}$ i $r_{2 н с}$ - сума активних зведених опорів вторинної обмотки трансформатора та навантаження за відповідними осями; $r_{m}$ - активний опір гілки намагнічування заступної Т-подібної схеми трансформатора.

Останнім часом спостерігається намагання уточнення ММ трансформатора за рахунок зменшення кількості припущень, одним 3 котрих являється неврахування магнітних втрат. Так у роботах $[14,15]$ наведені ММ з врахуванням втрат потужності у магнітопроводі, виконується це за рахунок введення у систему рівнянь (4) додаткової складової $3 r_{m}$, у скобках котрої фактично розраховується струм гілки намагнічування. Така уточнена ММ має більшу адекватність [14], яка особливо необхідна при моделюванні перехідних процесів при різних умовах: від режиму холостого ходу до короткого замкнення.

У зв'язку з моделюванням асиметричних режимів використання загального вектору зображення на постійному струмі недоцільне, тому що необхідно отримати зміну струмів за кожною фазою, а відповідно за кожною віссю.

Виходячи з зазначеного, моделювання виконується на змінному струмі, а первинні напруги задаються наступним чином у в.о.:

$$
\left\{\begin{array}{l}
U_{1 a}=\sqrt{2} \sin (\omega t) \\
U_{1 b}=\sqrt{2} \sin \left(\omega t+\frac{2}{3 \pi}\right) \\
U_{1 a}=\sqrt{2} \sin \left(\omega t-\frac{2}{3 \pi}\right)
\end{array}\right.
$$

де $\omega=2 \pi f-$ кутова частота напруги мережі.

Визначення результуючих перехідних процесів для струмів можна виконати на підставі масштабування осьових струмів або їх проекції на відповідну вісь (фазу). При масштабуванні осьові струми достатньо помножити на коефіціснт 1,5 , а при знаходженні проекцій слід використати наступну загальну формулу для трифазної системи:

$$
I_{x}=i_{x}-0,5 i_{y}-0,5 i_{z},
$$

де $x$ - фаза (ось) за якою визначається струм; $y, z-$ інші дві фази (осі).

Поєднуючи системи рівнянь (3)-(5), можна виконати моделювання трансформатора у тому числі при асиметричних режимах роботи. Для прикладу розглядається моделювання трансформатора потужністю 40 кBA, на напругу 6 / 0,4 кВ, його параметри можна розрахувати 3 паспортних даних за методикою наведеною в [14], там же наведена система базових одиниць. Також слід відмітити, що моделювання виконується для випадку з'єднання обмоток трансформатора «зірка-зірка», тобто без нульового дроту. Інші типи з'єднань обмоток трансформатора також можна дослідити за допомогою 
запропонованої ММ, але у такому випадку необхідно виконати відповідні масштабування та адаптацію ММ згідно типу з'єднання.

Для початку з метою визначення адекватності моделі розраховуються перехідні процеси для симетричного режиму - вмикання на повну потужність (рис. 1).

Для первинних струмів (рис. 1, а) також наведено зміну вектору зображення струму $I_{1}$, котрий можна розрахувати шляхом моделювання на постійному струмі. Даний струм можна визначити за виразом:

$$
I_{1}=\sqrt{\left(i_{1 a}-0,5 i_{1 b}-0,5 i_{1 c}\right)^{2}+\frac{3}{4}\left(i_{1 b}-i_{1 c}\right)^{2}} .
$$

Враховуючи, що струм $I_{1}$ обгинає струми $I_{1 A}, I_{1 B}$ і $I_{1 C}$, можна зробити висновок, що математична модель працює адекватно. Взагалі аналізуючи характер перехідних процесів у первинній (рис. 1, а) i вторинній (рис. 1, б) обмотках, можна відмітити, що спостерігається коливальний процес з незначним сплеском струму на початку, а весь перехідний процес продовжується приблизно 0,03 с. При симетричному навантаженні після закінчення перехідного процесу всі струми за фазами однакові.

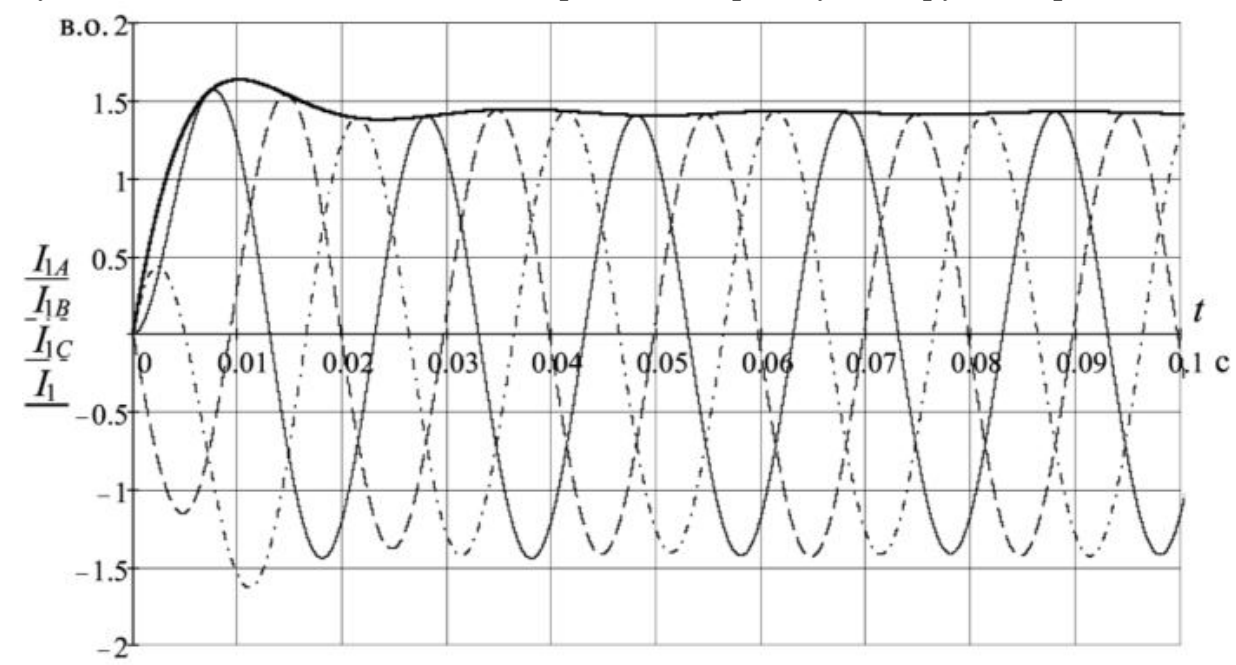

$\mathbf{a}$

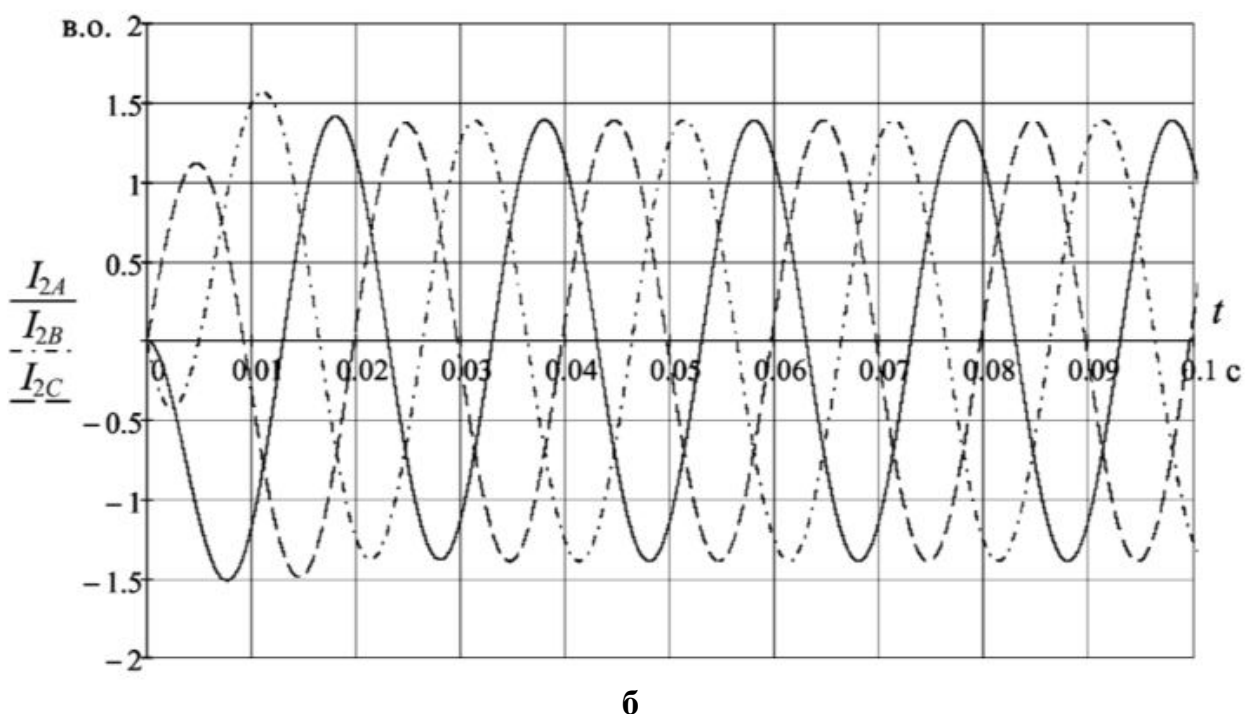

Рис. 1. Зміна первинних (а) та вторинних (б) струмів трансформатора при вмиканні на повне симетричне навантаження

Для розгляду алгоритму застосування наведеної ММ з метою моделювання асиметричних перехідних процесів обираються два 3 найбільш розповсюджених асиметричних аварійних режимів: однофазне коротке замкнення і обрив фази [16]. Це максимально стійкі й поширені асиметричні режими, ще одним найбільш вірогідним асиметричним режимом являється міжфазне коротке замкнення, але воно майже завжди виникає мінливо, тому що швидко переходить у трифазне симетричне коротке замкнення.

Для моделювання однофазного короткого замкнення у ММ трансформатора достатньо задати індуктивність $L_{\text {н.j }}$ навантаження $j$-тої фази рівною нулю, а активний опір $r_{2 н j}$ прийняти рівним 
зведеному активному опору вторинної обмотки трансформатора $r_{2}$. В даному випадку за $j$-ту фазу прийнято фазу $C$. Перерахувавши всі коефіцієнти, можна виконати моделювання однофазного короткого замкнення за системами рівнянь (3) і (4) з урахуванням рівнянь первинної напруги (5). Відповідні результати моделювання наведені на рис. 2, криві первинних (рис. 2, а) та вторинних (рис. 2, б) струмів однозначно демонструють асиметрію струмів, яка спричинена коротким замкненням у фазі $C$.

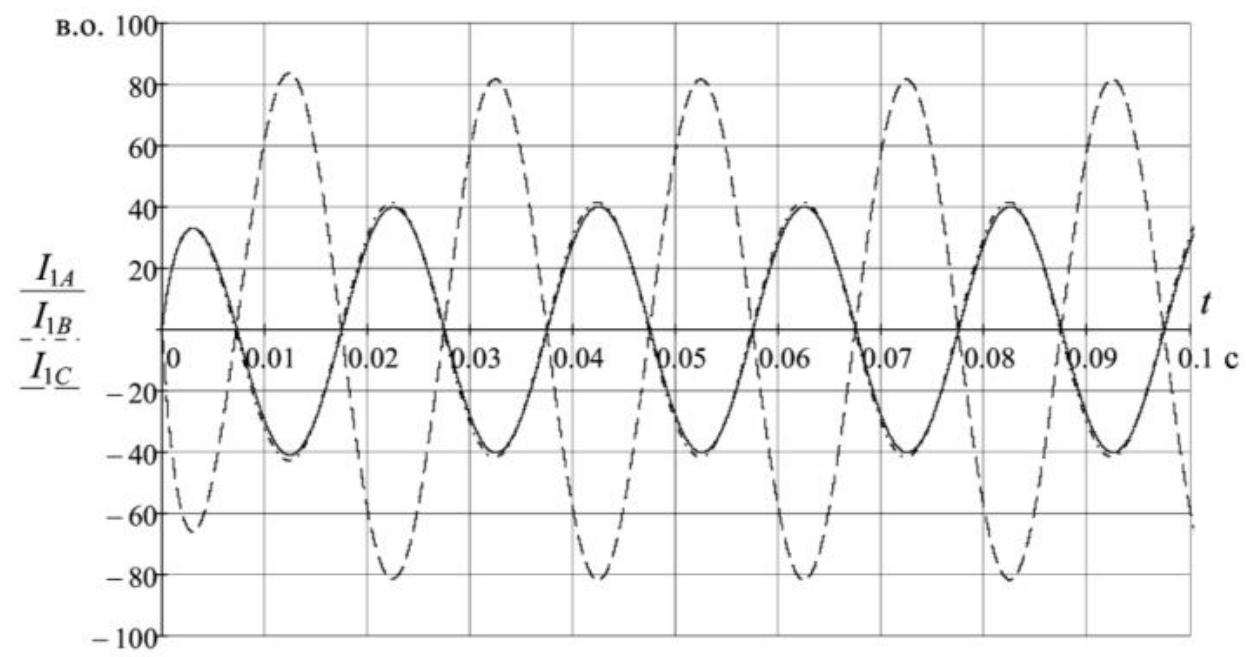

a

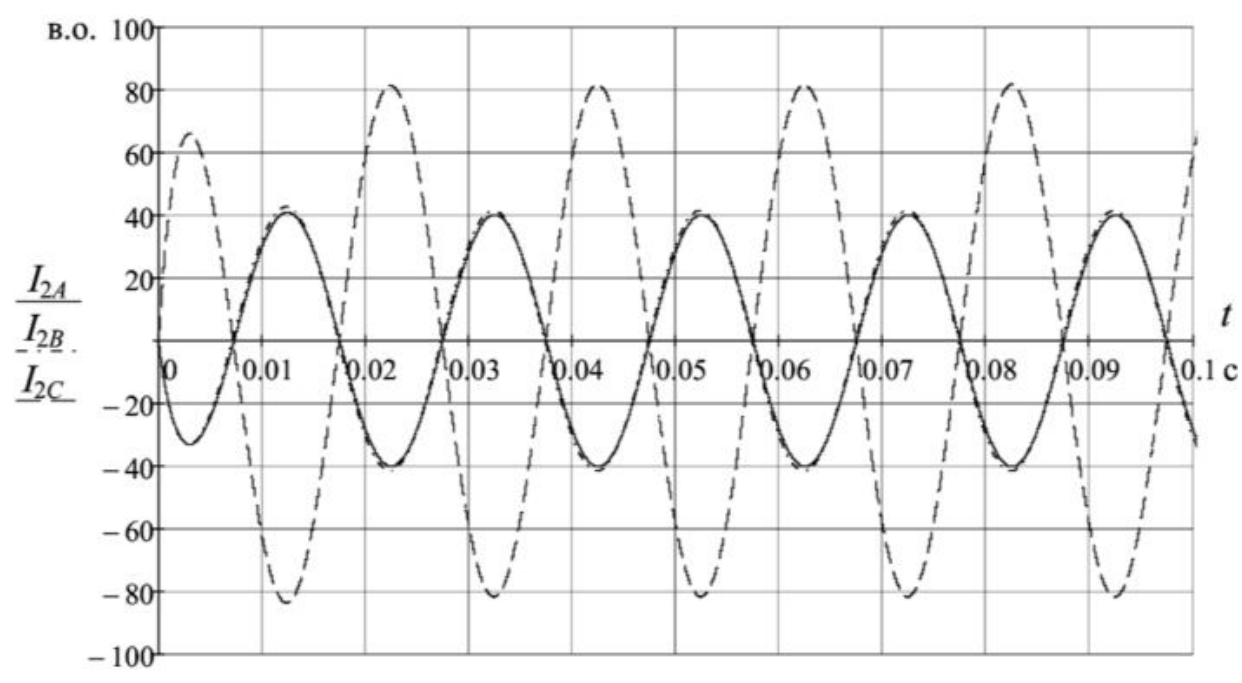

б

Рис. 2. Зміна первинних (а) та вторинних (б) струмів трансформатора при вмиканні на однофазне коротке замикання

Струм у фазі $C$ у двічі перевищує струм у фазах $A$ і $B$, крім того, за фазою струми у фазах $A$ i $B$ майже збігаються, а струм фази $C$ знаходиться у протилежності до них, це однаково справедливо для первинній і вторинній систем струмів (рис. 2).

Для моделювання перехідних процесів при обриві вторинної фази недостатньо змінити значення опорів однієї фази, як це зроблено у попередньому випадку. Слід враховувати, що струми двох фаз, які залишилися неушкодженими, відповідають одному у тому же струму - вторинному, якій при обриві вторинної фази відповідає струму навантаження подвійного опору, яке підключено на лінійну напругу. Тому у системі вторинних струмів виконуються зміни: 


$$
\left\{\begin{array}{l}
i_{2 a}=\frac{3 M}{\sqrt{2} k_{x}}\left[\frac{1}{L_{1 \sigma}}\left(\Psi_{1 a}\left(a_{1}-\frac{k_{x} L_{1 \sigma}}{M L_{2 \mathrm{H} a}}\right)+\Psi_{1 b} k_{2 c} L_{2 \mathrm{H} b}+\Psi_{1 c} k_{2 b} L_{2 \mathrm{H} c}\right)+\Psi_{2 a}\left(a_{2}+\frac{k_{x}}{M L_{2 \mathrm{\mu} a}}\right)+\Psi_{2 b} k_{2 c}+\Psi_{2 c} k_{2 b}\right]- \\
-\frac{3 M}{\sqrt{2} k_{x}}\left[\frac{1}{L_{1 \sigma}}\left(\Psi_{1 a} k_{2 c} L_{2 \mathrm{H} a}+\Psi_{1 b}\left(b_{1}-\frac{k_{x} L_{1 \sigma}}{M L_{2 \mathrm{H} b}}\right)+\Psi_{1 c} k_{2 a} L_{2 \mathrm{H} c}\right)+\Psi_{2 a} k_{2 c}+\Psi_{2 b}\left(b_{2}+\frac{k_{x}}{M L_{2 \mathrm{H} b}}\right)+\Psi_{2 c} k_{2 a}\right] \\
i_{2 b}=-i_{2 a} \\
i_{2 c}=0 .
\end{array}\right.
$$

3 урахуванням змін, які визначаються (6), прийняттям зведеного активного опору навантаження

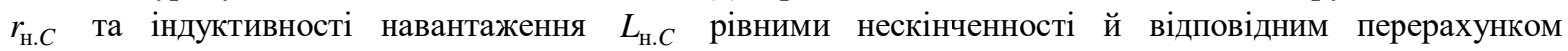
коефіцієнтів виконується моделювання трансформатора в режимі обриву фази $C$ у вторинній обмотці. Результати моделювання наведені на рис. 3.

На відміну від попередніх динамічних режимів (рис. 1) і (рис. 2) при обриві фази спостерігається суттєве розходження картини зміни первинних і вторинних струмів (рис. 3).

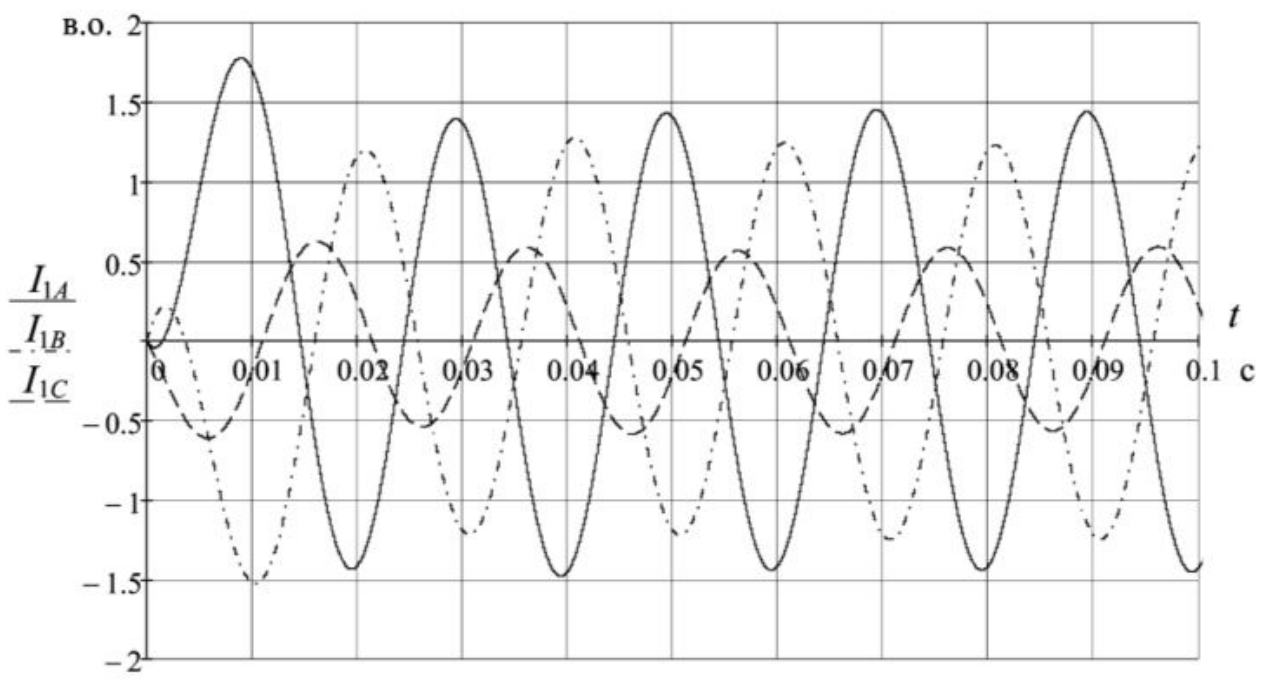

$\mathbf{a}$

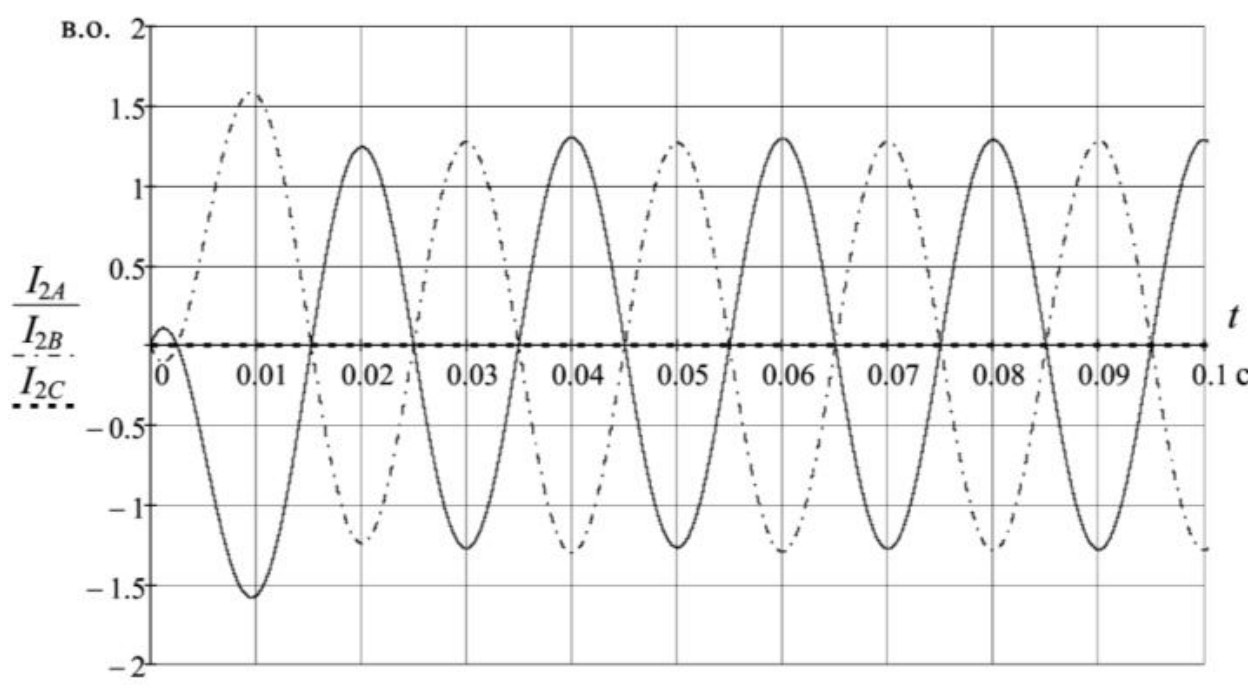

б

Рис. 3. Зміна первинних (а) та вторинних (б) струмів трансформатора при вмиканні з обривом однієї вторинної фази

Так первинні струми (рис. 3, а) хоча і мають різні амплітудні значення але майже зберігають взаємне розташування за фазами. При цьому вторинні струми в неушкоджених фазах перетворюються у один струм, тобто відносно кожної фази вони стають протилежними (рис. 3, б), що являється обгрунтуванням значної відміни картини струмів у первинній і вторинній системах. Таким чином можна 
відзначити суттєву асиметрію при однофазному короткому замкненні та обриві фази, яка визначається амплітудним та фазовим факторами.

Розглянуті підходи до моделювання типових асиметричних режимів шляхом параметричної та функціональної адаптації трьохосьової ММ трансформатора, яка дозволяє достатньо просто отримати криві перехідних струмів за кожною фазою. Такі широкі можливості та простота застосування свідчать про високий рівень універсальності ММ, тому їі слід розглядати, як основний інструмент моделювання динамічних режимів трифазних трансформаторів.

1. Визначена універсальна ММ трифазного трансформатора, яка може бути використана як для моделювання симетричних так і для моделювання асиметричних режимів.

2. Наведено підходи до параметричної та функціональної адаптації ММ до умов асиметричних режимів.

3. Простота запропонованої ММ полягає у відсутності необхідності розкладання асиметричних величин на відповідні симетричні складові (пряму, зворотну та нульову послідовності), що зменшує об' $€$ м розрахунків у два або три рази в залежності від кількості симетричних складових.

\section{Список використаної літератури}

1. Kimstach, O.Yu. Definition of Optimal Structure of Power Network // Problemele energeticii regionale, 2019, 1 (39), pp. 22-33. doi: http://doi.org/10.5281/zenodo.2650415

2. Faraj, M.A., Mousa, S.K., Shuaieb, W.S., Rifai, D., Ali, K., Abdalla, A.N. Power Transformer Modelling Based on Vector Fitting Method // IJESC, March 2020. Vol. 10. Issue No. 3, pp. 24798-24803.

3. Yasid N.F.M., Alawady A.A., Yousof M.F.M., Talib M.A., Kamarudin M.S. The Effect of short circuit fault in three-phase core-typed transformer // International Journal of Power Electronics and Drive System (IJPEDS). Vol. 11, No. 1, March 2020, pp. 409-416. doi: 10.11591/ijpeds.v11.i1.pp409-416

4. Septiawan H. Pre-energize Analysis on 3 Phase Transformer by Considering Each Phase Flux // JAREEJournal on Advance Research in Electrical Engineering. Volume3, Number 2, October 2019, pp. 135-139. doi: https://doi.org/10.12962/j25796216.v3.i2.90

5. Кімстач О.Ю., Жежело А.О., Агафонов О.В. Коротке замкнення між витками обмоток трансформатора // Актуальные научные исследования в современном мире. Журнал - ПереяславХмельницкий, 2019. - Вып. 6(50), ч. 6 - С. 29-34.

6. Копылов И.П. Математическое моделирование электрических машин / М.: Высш. шк., 2001. $327 \mathrm{c}$.

7. Bulucea C.A., Nicola D.A., Mastorakis N.E., Bulucea C.A. Three-phase power transformer modelling in AC/DC traction substations // MATEC Web of Conferences CSCC 2019. Volume 292 (2019) 01006. doi: https://doi.org/10.1051/matecconf/201929201006

8. Попов Г.В., Тихонов А.И., Климов Д.В. Математическая модель динамических режимов работы трансформатора на основе расчетов магнитного поля методом конечных элементов // Вестник ИГЭУ. Вып. 3. - 2007. - С. 11-15.

9. Однокопылов Г.И., Брагин А.Д. Математическая модель асинхронного двигателя в неполнофазном режиме работы // Известия Томского политехнического университета. Инжиниринг георесурсов, 2013. № 323 (4). С. 133-137.

10. Коршунов А. Математическая модель асинхронного трехфазного двигателя с фазным ротором, не использующая понятие вращающегося магнитного поля // Силовая электроника, 2019. № 6. С. 12-19.

11.Новаш И.В., Румянцев Ю.В. Расчет параметров модели трехфазного трансформатора из библиотеки MatLab-Simulink с учетом насыщения магнитопровода // Энергетика. Известия высших учебных заведений и энергетических объединений СНГ. 2015. №1. С. 12-24.

12. Мартынов В.А., Голубев А.Н., Евдаков А.Е. Анализ динамических режимов работы трехфазных трехстержневых трансформаторов в пакете Matlab // Вестник ИГЭУ. 2016. №4. С. 11-18.

13. Кузнецов В.В., Каланчин Д.Ю., Антонов Д.Б., Низовой А.Н. Моделирование электромагнитных переходных процессов в сетях с трехфазными силовыми трансформаторами // Вестник ВГТУ. 2011. Том 7, №1. C. 63-65.

14. Кімстач О.Ю., Загурський В.О. Урахування магнітних втрат потужності при моделюванні перехідних процесів у трансформаторах // Вісник Херсонського національного технічного університету. Херсон: ХНТУ, 2018. - Вип. 2 (65) - С. 182-189.

15. Пустоветов М.Ю. Математическая модель трехфазного трансформатора // Известия Томского политехнического университета. - Т. 321. № 4. - 2012. - С. 97-100.

16. Гусев, А.С., Свечкарев, С.В., Плодистый, И.Л. Универсальная математическая модель силовых трехфазных трансформаторов и автотрансформаторов // Известия Томского политехнического университета. Инжиниринг георесурсов, 2007. № 311 (4), С. 77-81. 


\section{References}

1. Kimstach, O.Yu. Definition of Optimal Structure of Power Network // Problemele energeticii regionale, 2019, 1 (39), pp. 22-33. doi: http://doi.org/10.5281/zenodo.2650415

2. Faraj, M.A., Mousa, S.K., Shuaieb, W.S., Rifai, D., Ali, K., Abdalla, A.N. Power Transformer Modelling Based on Vector Fitting Method // IJESC, March 2020. Vol. 10. Issue No. 3, pp. 24798-24803.

3. Yasid N.F.M., Alawady A.A., Yousof M.F.M., Talib M.A., Kamarudin M.S. The Effect of short circuit fault in three-phase core-typed transformer // International Journal of Power Electronics and Drive System (IJPEDS). Vol. 11, No. 1, March 2020, pp. 409-416. doi: 10.11591/ijpeds.v11.i1.pp409-416

4. Septiawan H. Pre-energize Analysis on 3 Phase Transformer by Considering Each Phase Flux // JAREEJournal on Advance Research in Electrical Engineering. Volume3, Number 2, October 2019, pp. 135-139. doi: https://doi.org/10.12962/j25796216.v3.i2.90

5. Kimstach O.Yu., Zhezhelo A.O., Ahafonov O.V. Korotke zamknennia mizh vytkamy obmotok transformatora [Turn-to-turn short circuit of transformer windings] // Aktual'nye nauchnye issledovanija $v$ sovremennom mire. Zhurnal - Perejaslav-Hmel'nickij, 2019. - Vyp. 6(50), ch. 6 - pp. 29-34.

6. Kopylov I.P. Matematicheskoe modelirovanie jelektricheskih mashin [Mathematical modelling of electrical machines] / M.: Vyssh. shk. 2001. - 327 p.

7. Bulucea C.A., Nicola D.A., Mastorakis N.E., Bulucea C.A. Three-phase power transformer modelling in AC/DC traction substations // MATEC Web of Conferences CSCC 2019. Volume 292 (2019) 01006. doi: https://doi.org/10.1051/matecconf/201929201006

8. Popov G.V., Tihonov A.I., Klimov D.V. Matematicheskaja model' dinamicheskih rezhimov raboty transformatora na osnove raschetov magnitnogo polja metodom konechnyh jelementov [The mathematical model of dynamic transformer working conditions on the basis of magnetic field calculations using finite element method] // Vestnik IGJeU. - Vyp. 3. - 2007. - pp. 11-15.

9. Odnokopylov G.I., Bragin A.D. Matematicheskaja model' asinhronnogo dvigatelja v nepolnofaznom rezhime raboty [Mathematical model of induction motor in phase failure mode] // Izvestija Tomskogo politehnicheskogo universiteta. Inzhiniring georesursov, 2013. № 323 (4). pp. 133-137.

10. Korshunov A. Matematicheskaja model' asinhronnogo trehfaznogo dvigatelja s faznym rotorom, ne ispol'zujushhaja ponjatie vrashhajushhegosja magnitnogo polja [Mathematical model of wound-rotor induction motor unused conception of rotating field] // Silovaja jelektronika, 2019. № 6. pp. 12-19.

11. Novash I.V., Rumjancev Ju.V. Raschet parametrov modeli trehfaznogo transformatora iz biblioteki MatLab-Simulink s uchetom nasyshhenija magnitoprovoda [Three-phase transformer parameters calculation considering the core saturation for the MatLab-Simulink transformer model] // Jenergetika. Izvestija vysshih uchebnyh zavedenij i jenergeticheskih obedinenij SNG. 2015. №1. pp. 12-24.

12. Martynov V.A., Golubev A.N., Yevdakov A.E. Analiz dinamicheskih rezhimov raboty trehfaznyh trehsterzhnevyh transformatorov v pakete Matlab [Matlab analysis of dynamic modes of three-phase three-core transformers] // Vestnik IGJeU. 2016. №4. pp. 11-18.

13. Kuznecov V.V., Kalanchin D.Ju., Antonov D.B., Nizovoj A.N. Modelirovanie jelektromagnitnyh perehodnyh processov v setjah s trehfaznymi silovymi transformatorami [Modelling of electromagnetic transients in networks with three-phase power transformers] // Vestnik VGTU. 2011. Tom 7, № 1. pp. 63-65.

14. Kimstach O.Yu., Zahurskyi V.O. Urakhuvannia mahnitnykh vtrat potuzhnosti pry modeliuvanni perekhidnykh protsesiv $\mathrm{u}$ transformatorakh [Taking into account magnetic losses in the simulation of transformer transients] // Visnyk Khersonskoho natsionalnoho tekhnichnoho universytetu. - Kherson: KhNTU, 2018. - Vyp.2 (65) - pp. 182-189.

15. Pustovetov M.Ju. Matematicheskaja model' trehfaznogo transformatora [Mathematical model of threephase transformer] // Izvestija Tomskogo politehnicheskogo universiteta. - T. 321. № 4. - 2012. - pp. 97-100.

16. Gusev, A.S., Svechkarev, S.V., Plodistyj, I.L. Universal'naja matematicheskaja model' si-lovyh trehfaznyh transformatorov $\mathrm{i}$ avtotransformatorov [Universal mathematical model of power three-phase transformers and autotransformers] // Izvestija Tomskogo politehnicheskogo universiteta. Inzhiniring georesursov, 2007. № 311 (4), pp. 77-81. 